\title{
Evaluation of surrogate animal models of melioidosis
}

\author{
Jonathan Mark Warawa* \\ Center for Predictive Medicine, Department of Microbiology and Immunology, University of Louisville, Louisville, KY, USA
}

Edited by:

Kenneth Fields, University of Miami, USA

\section{Reviewed by:}

Alfredo G. Torres, University of Texas Medical Branch, USA

Martin I. Voskuil, University of Colorado Denver, USA

\section{${ }^{*}$ Correspondence:}

Jonathan Mark Warawa, Center for Predictive Medicine, University of Louisville, 505 S. Hancock St., CTRB 619, Louisville, KY 40202, USA. e-mail: jonathan.warawa@louisville.edu
Burkholderia pseudomallei is the Gram-negative bacterial pathogen responsible for the disease melioidosis. B. pseudomallei establishes disease in susceptible individuals through multiple routes of infection, all of which may proceed to a septicemic disease associated with a high mortality rate. B. pseudomallei opportunistically infects humans and a wide range of animals directly from the environment, and modeling of experimental melioidosis has been conducted in numerous biologically relevant models including mammalian and invertebrate hosts. This review seeks to summarize published findings related to established animal models of melioidosis, with an aim to compare and contrast the virulence of $B$. pseudomallei in these models. The effect of the route of delivery on disease is also discussed for intravenous, intraperitoneal, subcutaneous, intranasal, aerosol, oral, and intratracheal infection methodologies, with a particular focus on how they relate to modeling clinical melioidosis. The importance of the translational validity of the animal models used in B. pseudomallei research is highlighted as these studies have become increasingly therapeutic in nature.

Keywords: mouse, hamster, infant diabetic rat, non-human primate, pneumonia, septicemia, inflammatory response

\section{INTRODUCTION}

Burkholderia pseudomallei is the etiologic agent of the disease melioidosis which is endemic in Southeast Asia and northern Australia. B. pseudomallei can be cultured from tropical soils without requiring a host for environmental persistence (Kaestli et al., 2009), and B. pseudomallei infections of both mammalian and nonmammalian hosts are considered to be opportunistic. Melioidosis is historically associated with a high mortality rate due to the speed with which septicemia develops and the inherent resistance of the bacteria to several classes of antibiotics. The overall mortality rate of melioidosis in endemic areas of Australia is 19\%, while it is 50\% in Thailand, likely reflecting the differing availability of efficacious treatment (Limmathurotsakul et al., 2010a).

Exposure to B. pseudomallei in endemic areas is considered high, with seroconversion rates as high as $80 \%$ by the age of 4 , whereas only $0.0045 \%$ of the population annually contracts disease (Leelarasamee, 1998). The significant gap between the incidence of exposure and disease suggests the role of additional factors such as dose, route of infection, and host susceptibility to disease. B. pseudomallei is present in tropical soils at an average density of $700 \mathrm{CFU} / \mathrm{g}$ of soil in rice fields where the likelihood for opportunistic interaction with humans is high, whereas transient increases in the soil titer to $>10,000 \mathrm{CFU} / \mathrm{g}$ may increase the likelihood that susceptible individuals may contract disease (Limmathurotsakul et al., 2010b). Human risk factors for melioidosis include diabetes, severe alcoholism, thalassemia, and renal complications, where diabetes mellitus represents the predominant risk factor in $37-60 \%$ of melioidosis patients (Cheng and Currie, 2005).

A wide variety of animals are opportunistically infected with B. pseudomallei from the environment, where the increased incidence of melioidosis amongst certain animal species has led to conclusions regarding the susceptibility to infection. In northern Australia, several livestock species are considered particularly sensitive to infection including goats, sheep, camels, and alpacas (Choy et al., 2000). Pigs and deer are moderately sensitive to infection, while cats, dogs, birds, and cattle are only partially sensitive to infection (Choy et al., 2000). Numerous additional animal species have been reported to contract melioidosis, many of which represent introductions of non-native species to $B$. pseudomallei-associated environments, as in the case of zoos and aquariums in endemic areas (Hicks et al., 2000; Sprague and Neubauer, 2004).

Genome sequencing has revealed that $B$. pseudomalle $i$ is closely related to Burkholderia mallei, an obligate mammalian pathogen responsible for the disease glanders. $B$. mallei is considered to be a clone of $B$. pseudomallei, having underwent genomic reduction which decreased its genome size from 7.2 to $5.8 \mathrm{Mb}$ (Nierman et al., 2004). B. mallei does not possess ability to survive in the environment for prolonged periods of time, and the natural host range has been reduced to soliped reservoirs from which opportunistic zoonotic infections occur. Successful eradication of B. mallei from westernized countries over the last century was made possible by the limited host range of $B$. mallei, and a simple diagnostic test that identified infected horses to be culled (Derbyshire, 2002).

Both B. pseudomallei and B. mallei are Category B Select Agent BSL-3 pathogens identified to possess a potential for bioweaponization. Licensed vaccines are not currently available for prophylactic protection against either pathogen and post-exposure prophylaxis options are limited. Thus, numerous studies have described animal models used in the study of the diseases caused by these closely related organisms with an aim to facilitate the investigation of novel therapeutics. A much larger body of research has focused on modeling the disease of $B$. pseudomallei in animals, and as such, this review will focus primarily on summarizing our current understanding of disease progression and host immune response in laboratory models of animal melioidosis. 


\section{CLINICAL MELIOIDOSIS}

Burkholderia pseudomallei is maintained in tropical soils worldwide and opportunistically infects a wide range of hosts including mammalian, avian, and invertebrate species. B. pseudomalle $i$ is infectious to humans by several routes of infection including percutaneous inoculation, ingestion, inhalation, and less commonly by sexual transmission or mother-to-fetus transmission (McCormick et al., 1975; Currie et al., 2000c; Inglis et al., 2000a; Abbink et al., 2001). In endemic areas, percutaneous inoculation is thought to represent the most common mechanism of transmission, although identifying the route of infection in the absence of a clear inoculating event may be difficult due to the systemic spread of melioidosis to all major organs, rather than containment of disease to the site of infection (Currie et al., 2000c).

Melioidosis is a disease that manifests with a wide range of symptoms including pneumonia, skin lesions, neurological infections, osteomyelitis, genitourinary infections, prostatic abscesses, pericarditis, and septic arthritis (Currie et al., 2000b; Morse et al., 2009; Chetchotisakd et al., 2010). Pulmonary infections occur in approximately half of all melioidosis patients, and represents the most common presentation of disease. The incubation period averages 9 days before the onset of symptoms (Currie et al., 2000c), and septicemia is a highly fatal progression of melioidosis with mortality approaching $70 \%$ for untreated disease (Chaowagul et al., 1989).

Diagnostic imaging of melioidosis has revealed that the lung is the most frequently affected organ in clinical patients (Muttarak et al., 2008; Lim and Chong, 2010). Liver and spleen pathology is observed in approximately half of melioidosis patients, suggesting that colonization of these organs typically occurs at reduced rates relative to the lung (Lim and Chong, 2010). The size and frequency of splenic lesions in melioidosis are unique as many bacterial pathogens do not share the same level of spleen pathology as that elicited by B. pseudomallei (Laopaiboon et al., 2009). Histological analyses have found that B. pseudomallei may be found within macrophages in the lung, liver, and spleen as well as in extracellular niches (Wong et al., 1995, 1996).

Cytokine profiles of clinical melioidosis indicate that B. pseudomallei elicits a strong proinflammatory response. The synergistic production of IFN- $\gamma$ by IL-12, IL-15, and IL-18 was observed in melioidosis patients with all four cytokines present in plasma at levels above background in non-septicemic patients, and the onset of septicemic melioidosis further elevated the levels of these proinflammatory cytokines (Lauw et al., 1999). Similarly, fatal septicemic melioidosis is associated with plasma levels of the cytokines TNF- $\alpha$, IL- 6 , and IL-10 that are elevated above the levels of surviving patients (Simpson et al., 2000), and the T-cell chemoattractants IP-10 and MIG are also elevated in melioidosis patients, particularly during septicemia (Lauw et al., 2000). It is not clear whether elevated proinflammatory cytokine levels contribute to poor outcome or are solely an indicator of disease severity (Brown et al., 1991; Friedland et al., 1992; Suputtamongkol et al., 1992).

\section{MOUSE MODEL}

The mouse represents the most common animal model used as a surrogate for the study of melioidosis. Numerous commercially available tools are available to study gene regulation, immunology, and cell biology in mice, making the mouse an attractive translational research model for studying disease. This section will review our current understanding of disease progression and host response to B. pseudomallei in the mouse model.

\section{MOUSE STRAIN SUSCEPTIBILITY}

Numerous mouse strains have been used to model melioidosis, including BALB/c, C57BL/6, SWISS, CBA, CD-1, DBA/2, C3H/ HeN, Namru Albino, Taylor Outbred (TO), 129/SvEv, and SCID mice, however little is known about the effect of the host mouse strain in mediating susceptibility to infection with $B$. pseudomallei. BALB/c mice have long been known to represent a susceptible mouse strain which are used to model the acute form of the disease, whereas C57BL/6 are thought to be relatively resistant to B. pseudomallei infection resulting in a chronic disease model (Leakey et al., 1998). Thus, by several routes of infection, fewer organisms are required to establish disease in the $\mathrm{BALB} / \mathrm{c}$ model as compared to the C57BL/6 mice. The specific fold difference in susceptibility to infection of these two mouse strains varies not only by route of infection, but also on strain of B. pseudomallei used in the infection challenge. By intravenous infection, $10^{2}$ - to $6.25 \times 10^{4}$-fold more B. pseudomallei are required to infect C57BL/6 mice, 13 - to $2 \times 10^{4}$-fold by intraperitoneal infection, 18 - to $1 \times 10^{5}$-fold by subcutaneous infection or 13 - to 390 -fold by intranasal infection (Tables 1 and 2). A log-transformed average of this data suggests that a $\sim 200$-fold difference in susceptibility exists between BALB/c and C57BL/6 melioidosis models.

Several studies have further investigated the susceptibility of other mouse strains to infection with B. pseudomallei. A study using age and sex matched mice challenged with a common strain of $B$. pseudomallei revealed that the susceptibility of four mouse strains to intravenous infection was ordered as $\mathrm{BALB} / \mathrm{c}>\mathrm{DBA} / 2>\mathrm{C} 3 \mathrm{H} /$ HeN $>>$ C57BL/6 (Hoppe et al., 1999). Another study has reported that CBA mice are approximately 40 -fold more sensitive to infection than BALB/c mice (Manzeniuk et al., 1999), and may represent the most sensitive mouse model for the study of melioidosis. The 129/ SvEv mice are 23-fold more sensitive than BALB/c mice and TO mice are over 200 -fold more resistant than BALB/c mice (Table 1 ), indicating that $\mathrm{C} 57 \mathrm{BL} / 6$ mice may be as resistant to infection as outbred mice. CD-1 mice are the only additional outbred mouse strain used in the study of B. pseudomallei pathogenesis (Fisher et al., 1971), however $\mathrm{LD}_{50}$ information is not available to address susceptibility to melioidosis. Summarizing the findings of these studies, the ranked susceptibility of mice to $B$. pseudomallei infection may be represented as $\mathrm{CBA}>129 / \mathrm{SvEv}>\mathrm{BALB} / \mathrm{c}>\mathrm{DBA} / 2>\mathrm{C} 3 \mathrm{H} /$ $\mathrm{HeN}>(\mathrm{C} 57 \mathrm{BL} / 6$ and $\mathrm{TO})$.

\section{ROUTES OF INFECTION}

Naturally occurring infections in the human population occur via several possible routes of infection including inhalation and ingestion, while percutaneous inoculations are thought to represent the primary route of infection in endemic areas (Currie et al., 2000c). These naturally occurring routes of infection have been studied in several different animal species with the aim of modeling clinical melioidosis. While percutaneous inoculation is thought to represent the primary natural route of infection, there has been a recent shift toward animal respiratory disease models. Biodefense 
Table 1 | Effect of mouse species on disease outcome.

\begin{tabular}{|c|c|c|c|c|c|c|c|}
\hline $\begin{array}{l}\text { Route of } \\
\text { infection }\end{array}$ & $\begin{array}{l}\text { Mouse } \\
\text { strain }\end{array}$ & Sex & Age & $\begin{array}{l}\text { Bacterial } \\
\text { strain }\end{array}$ & $\begin{array}{l}\mathrm{LD}_{50} \text { or ID } \\
\text { (CFU) }\end{array}$ & $\begin{array}{l}\text { Duration of } \\
\text { observation }\end{array}$ & Reference \\
\hline i.p. & $\mathrm{BALB} / \mathrm{c}$ & N.I. & N.I. & $\mathrm{A} 2$ & 19 & N.I. & Taweechaisupapong et al. (2005) \\
\hline i.p. & $\mathrm{BALB} / \mathrm{c}$ & Female & 6-8 weeks & $\mathrm{A} 2$ & 20 & 30 days & Srilunchang et al. (2009) \\
\hline i.p. & C57BL/6 & Female & 6-8 weeks & $\mathrm{A} 2$ & $3 \times 10^{2}$ & 30 days & Srilunchang et al. (2009) \\
\hline i.v. & $\mathrm{BALB} / \mathrm{c}$ & Mix & 6-10 weeks & $\mathrm{TGH}$ & 4 & 10 days & Leakey et al. (1998) \\
\hline i.v. & C57BL/6 & Mix & 6-10 weeks & $\mathrm{TGH}$ & $2.5 \times 10^{4}$ & 10 days & Leakey et al. (1998) \\
\hline i.p. & $\mathrm{TO}$ & Female & 10-12 weeks & $708 a$ & $>5 \times 10^{5}$ & 65 days & Santanirand et al. (1999) \\
\hline i.p. & 129/SvEv & N.I. & N.I. & $708 a$ & $1 \times 10^{2}$ & 65 days & Santanirand et al. (1999) \\
\hline i.p. & BALB/c & N.I. & N.I. & $708 a$ & $2.31 \times 10^{3}$ & N.I. & Titball et al. (2008) \\
\hline
\end{tabular}

i.p., Intraperitoneal; i.v., intravenous; N.I., not indicated.

spending following the anthrax letter attacks of September 2001 was pivotal in shifting this focus toward biodefense-related respiratory models for melioidosis.

\section{Intravenous}

Burkholderia pseudomallei infections by the intravenous (i.v.) route lead to a rapid disseminated infection affecting multiple organs, and represents the most acute disease model of melioidosis based on the low numbers of organisms required to cause disease. Infection by i.v. inoculation results in a rapidly fatal disease with mortality at 2-4 days (Leakey et al., 1998) and the primary organs colonized are liver and spleen with reduced numbers of organisms colonizing the lung (Hoppe et al., 1999). Systemic spread to the lung following non-pulmonary infection is consistent with clinical data where reports of percutaneous inoculation are frequently associated with presentation of pulmonary disease (Currie et al., 2000c).

Due to the very acute nature of the i.v. infection model, low virulence strains of $B$. pseudomallei or resistant strains of mice may be successfully studied in this model when disease cannot be achieved in more resistant models. For example, the i.v. model has been used to characterize a $6 \log$ range of disease-causing potential of over $40 \mathrm{~B}$. pseudomallei strains of clinical, veterinary, and environmental origin (Ulett et al., 2001). The i.v. model is also ideally situated to investigate therapeutic intervention for the most acute form of melioidosis. While the i.v. model enhances the acute disease potential for difficult to study strains of B. pseudomallei and animals, the limitations of the i.v. model relate to the short time span of melioidosis for basic studies of disease progression using highly virulent bacterial strains or susceptible animal models.

\section{Intraperitoneal}

The infection of mice by the intraperitoneal (i.p.) route is the second most acute mouse model of melioidosis as assessed by $\mathrm{LD}_{50}$ values. The i.p. $\mathrm{LD}_{50}$ values either closely mimic those identified for i.v. infection, or may be up to $10^{2}$-fold higher, depending on the bacteria and mouse strains used in the challenge (Table 2). B. pseudomallei i.p. infection results in colonization of the liver and spleen, whereas the lung is either not significantly affected (Santanirand et al., 1999) or colonized at a reduced level relative to respiratory disease models (Atkins et al., 2002).
The host environment encountered during i.p. infection involves host defense through peritoneal macrophages, and host susceptibility through access to major organs including the liver and spleen. Symptomatic disease may not occur until 6 days post-infection (Tan et al., 2008). The i.p. mouse model does not specifically model a natural route of infection for human melioidosis, but like the i.v. model, may model a traumatic percutaneous inoculation. As such, similar benefits and limitations exist for the i.p. model as the i.v. model where i.p. infections are useful for the study of rapid acute disease.

\section{Subcutaneous}

Subcutaneous (s.c.) mouse models are the third most acute models for study of melioidosis with $\mathrm{LD}_{50}$ values typically $10^{1}$ - to $10^{2}$-fold higher than those of i.p. models (Table 2). This model represents a good physical reproduction of the percutaneous infections associated with human disease. Lesion formation at the site of percutaneous inoculation is not consistently observed clinically (Currie et al., 2000c), and lesion formation has not been reported for s.c. mouse models. Needle inoculation by the s.c. route into the dermis and/or hypodermis skin layers of a mouse results in a delayed disease process compared to other routes of infection, as s.c. infections become symptomatic more than 2 weeks after i.p. infected mice (Tan et al., 2008). The host immune response to s.c. inoculation may involve macrophages, dendritic cells, mast cells, and lymphocytes associated with the dermis, whereas deeper inoculation of the hypodermis may not result in a significant initial host immune response to the invading bacteria. $B$. pseudomallei may spread through a host by invading blood vessels present in the hypodermal layer, and this physical barrier to immediate systemic spread could account for the delay in disease progression and $\sim 10^{2}$-fold increase in organisms required to cause disease relative to the i.v. route of infection (Table 2). It is notable that B. pseudomallei strain NCTC 13179 is reported to cause disease by s.c. inoculation of BALB/c mice with fewer organisms than is required by either i.p. or i.v. inoculation (Barnes and Ketheesan, 2005). Additional studies may be required to identify whether this is a unique susceptibility of $\mathrm{BALB} / \mathrm{c}$ mice to this particular strain of B. pseudomallei.

\section{Intranasal}

The target organ of i.n. inoculation is the lung which possesses several forms of innate immunoprotection against invading organisms. These host defenses include: (i) the physical barrier of mucus, (ii) 
Table 2 | Effect of route of infection on disease outcome.

\begin{tabular}{|c|c|c|c|c|c|c|c|}
\hline $\begin{array}{l}\text { Route of } \\
\text { infection }\end{array}$ & $\begin{array}{l}\text { Mouse } \\
\text { strain }\end{array}$ & Sex & Age & $\begin{array}{l}\text { Bacterial } \\
\text { strain }\end{array}$ & $\begin{array}{l}\mathrm{LD}_{50} \text { or ID } \\
\text { (CFU) }\end{array}$ & $\begin{array}{l}\text { Duration of } \\
\text { observation }\end{array}$ & Reference \\
\hline i.v. & $\mathrm{BALB} / \mathrm{c}$ & Female & 8-10 weeks & NCTC 7431 & $1 \times 10^{3}$ & 42 days & Hoppe et al. (1999) \\
\hline i.v. & $\mathrm{C} 3 \mathrm{H} / \mathrm{HeN}$ & Female & 8-10 weeks & NCTC 7431 & $6 \times 10^{3}$ & 42 days & Hoppe et al. (1999) \\
\hline i.v. & C57BL/6 & Female & 8-10 weeks & NCTC 7431 & $1 \times 10^{5}$ & 42 days & Hoppe et al. (1999) \\
\hline i.n. & $\mathrm{BALB} / \mathrm{c}$ & Female & 8-12 weeks & E8 & $<10$ & N.I. & Pilatz et al. (2006) \\
\hline i.v. & C57BL/6 & Mix & 8-10 weeks & NCTC 13178 & $5 \times 10^{3}$ & 10 days & Barnes and Ketheesan (2005) \\
\hline i.v. & $\mathrm{BALB} / \mathrm{c}$ & Mix & 8-16 weeks & NCTC 13178(CL24) & 10 & 10 days & Ulett et al. (2001) \\
\hline i.v. & $\mathrm{BALB} / \mathrm{c}$ & Mix & 8-10 weeks & NCTC 13178 & $<10$ & 10 days & Barnes and Ketheesan (2005) \\
\hline i.p. & C57BL/6 & Mix & 8-10 weeks & NCTC 13178 & $9.7 \times 10^{3}$ & 10 days & Barnes and Ketheesan (2005) \\
\hline i.n. & $\mathrm{BALB} / \mathrm{c}$ & Mix & 8-10 weeks & NCTC 13178 & $1.4 \times 10^{2}$ & 10 days & Barnes and Ketheesan (2005) \\
\hline Transoral & C57BL/6 & Mix & 8-10 weeks & NCTC 13178 & $1.8 \times 10^{6}$ & 10 days & Barnes and Ketheesan (2005) \\
\hline Transoral & $\mathrm{BALB} / \mathrm{c}$ & Mix & 8-10 weeks & NCTC 13178 & $7.2 \times 10^{3}$ & 10 days & Barnes and Ketheesan (2005) \\
\hline i.v. & C57BL/6 & Mix & 8-10 weeks & NCTC 13179 & $6 \times 10^{6}$ & 10 days & Barnes and Ketheesan (2005) \\
\hline i.v. & $\mathrm{BALB} / \mathrm{c}$ & Mix & 8-16 weeks & NCTC 13179(CL07) & $1.52 \times 10^{4}$ & 10 days & Ulett et al. (2001) \\
\hline i.v. & $\mathrm{BALB} / \mathrm{c}$ & Mix & 8-10 weeks & NCTC 13179 & $9 \times 10^{3}$ & 10 days & Barnes and Ketheesan (2005) \\
\hline i.p. & C57BL/6 & Mix & 8-10 weeks & NCTC 13179 & $6 \times 10^{6}$ & 10 days & Barnes and Ketheesan (2005) \\
\hline i.p. & $\mathrm{BALB} / \mathrm{c}$ & Mix & 8-10 weeks & NCTC 13179 & $4.7 \times 10^{5}$ & 10 days & Barnes and Ketheesan (2005) \\
\hline s.c. & C57BL/6 & Mix & 8-10 weeks & NCTC 13179 & $>10^{8}$ & 10 days & Barnes and Ketheesan (2005) \\
\hline s.c. & BALB/c & Mix & 8-10 weeks & NCTC 13179 & $9 \times 10^{2}$ & 10 days & Barnes and Ketheesan (2005) \\
\hline s.c. & $\mathrm{BALB} / \mathrm{c}$ & Female & 4-8 weeks & $\mathrm{KWH}$ & $5 \times 10^{5}$ & 20 days & Tan et al. (2008) \\
\hline s.c. & C57BL/6 & Female & $4-8$ weeks & $\mathrm{KWH}$ & $2.3 \times 10^{7}$ & 20 days & Tan et al. (2008) \\
\hline i.n. & $\mathrm{BALB} / \mathrm{c}$ & N.D. & 5-6 weeks & $\mathrm{KWH}$ & 45 & 10 days & Liu et al. (2002) \\
\hline i.n. & C57BL/6 & N.D. & 5-6 weeks & $\mathrm{KWH}$ & $4.85 \times 10^{3}$ & 10 days & Liu et al. (2002) \\
\hline i.n. & $\mathrm{BALB} / \mathrm{c}$ & Female & $4-8$ weeks & $\mathrm{KWH}$ & 16 & 10 days & Tan et al. (2008) \\
\hline i.n. & C57BL/6 & Female & 4-8 weeks & $\mathrm{KWH}$ & $6.23 \times 10^{3}$ & 10 days & Tan et al. (2008) \\
\hline Aerosol & $\mathrm{BALB} / \mathrm{c}$ & Female & 4-8 weeks & $\mathrm{KWH}$ & $<20$ & 10 days & Tan et al. (2008) \\
\hline Aerosol & C57BL/6 & Female & $4-8$ weeks & $\mathrm{KWH}$ & 423 & 10 days & Tan et al. (2008) \\
\hline i.p. & $\mathrm{BALB} / \mathrm{c}$ & Female & 4-8 weeks & K96243 & $5.4 \times 10^{4}$ & 10 days & Tan et al. (2008) \\
\hline i.p. & $\mathrm{BALB} / \mathrm{c}$ & Female & 5-6 weeks & K96243 & $\sim 1 \times 10^{3}$ & N.I. & Harland et al. (2007) \\
\hline i.p. & $\mathrm{BALB} / \mathrm{c}$ & N.I. & N.I. & K96243 & $2.62 \times 10^{2}$ & N.I. & Titball et al. (2008) \\
\hline i.p. & $\mathrm{BALB} / \mathrm{c}$ & Female & 6 weeks & K96243 & $3.5 \times 10^{3}$ & N.I. & Sarkar-Tyson et al. (2009) \\
\hline i.p. & C57BL/6 & Female & 4-8 weeks & K96243 & $5.3 \times 10^{6}$ & 10 days & Tan et al. (2008) \\
\hline s.c. & $\mathrm{BALB} / \mathrm{c}$ & Female & $4-8$ weeks & K96243 & $3 \times 10^{7}$ & 20 days & Tan et al. (2008) \\
\hline s.c. & C57BL/6 & Female & 4-8 weeks & K96243 & $5.4 \times 10^{8}$ & 20 days & Tan et al. (2008) \\
\hline i.n. & $\mathrm{BALB} / \mathrm{c}$ & Female & $4-8$ weeks & K96243 & $2.3 \times 10^{2}$ & 10 days & Tan et al. (2008) \\
\hline i.n. & C57BL/6 & Female & 4-8 weeks & K96243 & $1.52 \times 10^{4}$ & 10 days & Tan et al. (2008) \\
\hline Aerosol & BALB/c & Female & 6 weeks & K96243 & 5 & N.I. & Sarkar-Tyson et al. (2009) \\
\hline i.p. & $\mathrm{BALB} / \mathrm{c}$ & N.I. & $6-8$ weeks & $1026 b$ & $10^{4}$ & 30 days & Wikraiphat et al. (2009) \\
\hline
\end{tabular}


Table 2 | Continued

\begin{tabular}{|c|c|c|c|c|c|c|c|}
\hline $\begin{array}{l}\text { Route of } \\
\text { infection }\end{array}$ & $\begin{array}{l}\text { Mouse } \\
\text { strain }\end{array}$ & Sex & Age & $\begin{array}{l}\text { Bacterial } \\
\text { strain }\end{array}$ & $\begin{array}{l}\text { LD }_{50} \text { or ID } \\
\text { (CFU) }\end{array}$ & $\begin{array}{l}\text { Duration of } \\
\text { observation }\end{array}$ & Reference \\
\hline i.n. & $B A L B / c$ & Female & 6-8 weeks & $1026 b$ & $9.9 \times 10^{2}$ & N.I. & Goodyear et al. (2009) \\
\hline Aerosol & BALB/C & Female & 6-8 weeks & $1026 b$ & 10 & N.I. & Jeddeloh et al. (2003) \\
\hline Aerosol & C57BL/6 & Female & $6-8$ weeks & $1026 b$ & 27 & N.I. & Jeddeloh et al. (2003) \\
\hline i.n. & $B A L B / c$ & Female & $6-8$ weeks & DD503 & $1.38 \times 10^{3}$ & 14 days & Warawa et al. (2009) \\
\hline Aerosol & BALB/C & Female & 6-8 weeks & DD503 & $1.47 \times 10^{3}$ & N.I. & Jeddeloh et al. (2003) \\
\hline Aerosol & $\mathrm{BALB} / \mathrm{c}$ & Female & N.I. & DD503 & $1 \times 10^{3}$ & 39 days & Ulrich et al. (2004) \\
\hline i.p. & $\mathrm{BALB} / \mathrm{c}$ & N.I. & N.I. & $\mathrm{BRI}$ & 53 & N.I. & Titball et al. (2008) \\
\hline Aerosol & $\mathrm{BALB} / \mathrm{c}$ & Female & 6-8 weeks & $\mathrm{BRI}$ & 5 & 5 days & Lever et al. (2009) \\
\hline i.p. & $B A L B / C$ & Female & $6-8$ weeks & NCTC $4845^{\top}$ & 40 & 35 days & Nelson et al. (2004) \\
\hline Aerosol & $\mathrm{BALB} / \mathrm{c}$ & Female & 6-8 weeks & NCTC $4845^{\top}$ & 5 & 35 days & Nelson et al. (2004) \\
\hline i.p. & $\mathrm{BALB} / \mathrm{c}$ & Female & 4-8 weeks & EB6103 & $3.39 \times 10^{4}$ & 10 days & Tan et al. (2008) \\
\hline i.p. & C57BL/6 & Female & 4-8 weeks & EB6103 & $>8.5 \times 10^{5}$ & 10 days & Tan et al. (2008) \\
\hline s.c. & $\mathrm{BALB} / \mathrm{c}$ & Female & 4-8 weeks & EB6103 & $1.3 \times 10^{6}$ & 20 days & Tan et al. (2008) \\
\hline S.c. & C57BL/6 & Female & 4-8 weeks & EB6103 & $4.7 \times 10^{7}$ & 20 days & Tan et al. (2008) \\
\hline i.n. & BALB/C & Female & 4-8 weeks & EB6103 & $>8.5 \times 10^{2}$ & 10 days & Tan et al. (2008) \\
\hline i.n. & C57BL/6 & Female & 4-8 weeks & EB6103 & $2.2 \times 10^{4}$ & 10 days & Tan et al. (2008) \\
\hline i.p. & Namru albino & Female & 2-6 months & $103-67$ & 35 & N.I. & Dannenberg and Scott (1958) \\
\hline Aerosol & Namru albino & N.I. & 2-6 months & $103-67$ & 16 & N.I. & Dannenberg and Scott (1958) \\
\hline i.c. & Namru albino & Female & 3-4 weeks & $103 R$ & $1.6 \times 10^{4}$ & N.I. & Nigg et al. (1956) \\
\hline i.c. & Namru albino & Female & 3-4 weeks & 103R-2 & $1.6 \times 10^{2}$ & N.I. & Nigg et al. (1956) \\
\hline i.p. & CBA & N.D. & N.I. & C-141 & $5.8 \times 10^{2}$ & 45 days & Manzeniuk et al. (1999) \\
\hline i.p. & $\mathrm{BALB} / \mathrm{c}$ & N.D. & N.I. & C-141 & $1.5 \times 10^{4}$ & 45 days & Manzeniuk et al. (1999) \\
\hline S.C. & CBA & N.D. & N.I. & C-141 & $2.0 \times 10^{3}$ & 45 days & Manzeniuk et al. (1999) \\
\hline s.c. & BALB/C & N.D. & N.I. & C-141 & $1.1 \times 10^{5}$ & 45 days & Manzeniuk et al. (1999) \\
\hline i.p. & SWISS & Female & 8 weeks & 008 & $4.0 \times 10^{5}$ & 42 days & Valade et al. (2004) \\
\hline S.c. & SWISS & Female & 8 weeks & 008 & $6.3 \times 10^{6}$ & 42 days & Valade et al. (2004) \\
\hline i.n. & SWISS & Female & 8 weeks & 008 & $1.6 \times 10^{2}$ & 42 days & Valade et al. (2004) \\
\hline
\end{tabular}

i.v., Intravenous; i.p., intraperitoneal; i.n., intranasal; s.c., subcutaneous; i.c., intracranial; N.I., not indicated.

ciliary clearance of mucus from the lung, and (iii) rapid epithelial cell signaling of immunoprotection, including antimicrobial peptides and activation of resident alveolar macrophages. Host defense mechanisms of the lung trigger proinflammatory responses that are likely subverted by $B$. pseudomallei to breach the alveolar epithelial lining. B. pseudomallei readily colonizes the lung and is found to disseminate to other organs, notably the liver and spleen, following i.n. infection (Liu et al., 2002; Chua et al., 2003; Pilatz et al., 2006; Goodyear et al., 2009; Warawa et al., 2009). As discussed earlier, the tropism for lung colonization may be strain dependent as certain B. pseudomallei strains do not preferentially colonize the lung following intranasal delivery (Barnes and Ketheesan, 2005).

Respiratory tract infections established by intranasal (i.n.) delivery fail to follow a specific trend when comparing i.n. $\mathrm{LD}_{50}$ values to the previously described needle-associated routes of infection (i.v., i.p. and s.c.). Approximately $10^{1}-10^{2}$ fewer organisms are required to cause disease by the i.n. route relative to the i.p. route (Table 2), with examples of $10^{3}$-fold fewer organisms in the case of strain 008 infection of SWISS mice (Valade et al., 2004). The opposite trend is also observed where $>10^{1}$-fold more of strain NCTC 13179 organisms are required to cause disease by the i.n. route versus the i.p. route in infections of both BALB/c and C57BL/6 mice (Barnes and Ketheesan, 2005). Similar lack of correlation of i.v. and i.n. $\mathrm{LD}_{50}$ values are also observed (Table 2). Thus, the lack of correlation of respiratory $\mathrm{LD}_{50}$ values to those of the systemic (i.v., i.p., and s.c.) routes suggest that some $B$. pseudomallei strains are more adept establishing respiratory infections than others, or conversely that strains may be more adept at establishing systemic infections. For example, the highly virulent B. pseudomallei strain NCTC 13178 colonizes the lung at low levels regardless of whether it is delivered intranasally or by needle inoculation (Barnes and Ketheesan, 2005), suggesting that the high virulence of this strain may be attributed to its ability to rapidly disseminate and establish systemic disease rather than colonize the lung. Future studies will be required to identify genetic loci that contribute to the varied fitness of $B$. pseudomallei to establish respiratory and/or systemic diseases.

While, i.n. infections are thought to predominantly model lower respiratory tract infections of the lung, several additional host sites are infected. Bacterial suspensions deposited at the anterior nares resolve into three fluid fractions localizing to: (i) the upper respiratory tract, (ii) the lower respiratory tract, and (iii) the digestive system. The swallowing of a portion of the inoculum leads to an infection of the digestive system, which is not thought to be a major route of infection. B. pseudomallei has been demonstrated to successfully colonize both the upper and lower respiratory tracts, both of which can independently 
lead to disseminated disease. Luminescent B. pseudomallei used to infect mice intranasally were found to significantly colonize the upper respiratory tract, as indicated by in vivo visualization, and were also able to disseminate to the liver and spleen (Owen et al., 2009). Owen et al. argued that non-pulmonary invasion of the nasal-associated lymphoid tissue (NALT) is a significant route of host entry in intranasally infected mice, leading to disseminated infection of liver and spleen. Furthermore, significant B. pseudomallei colonization of the upper respiratory tract leads to meningitis through infection of the olfactory bulb, as has been similarly reported by others (Warawa and Gherardini, 2010). The upper respiratory tract represents a major site of colonization in intranasally infected mice as upper respiratory lavage of infected $\mathrm{BALB} / \mathrm{c}$ and $\mathrm{C} 57 \mathrm{BL} / 6$ mice have increased levels of the inflammatory cytokines IFN- $\gamma$, TNF- $\alpha$ and IL-1 $\beta$ (Liu et al., 2002). The clinical incidence of $B$. pseudomallei meningitis is considered to be uncommon (Currie et al., 2000a; Chadwick et al., 2002), thus animal models that frequently introduce meningitis may not accurately model clinical melioidosis. Thus, i.n. infections of mice may over-represent the clinical incidence of meningitis, and may also result in non-pulmonary dissemination via the NALT. The use of the i.n. model to study respiratory melioidosis benefits from the ease of use of the method and the relative safety to the researcher.

\section{Aerosol}

Aerosol infection of mice is optimized to deliver small infectious particles of an ideal size that are inhaled deep into the lung to establish pulmonary infection. The most efficacious particle size required to maximize pulmonary distribution will depend upon the dynamics of breathing, which will vary amongst species, age, and sex (Kim and Hu, 1998; Thomas et al., 2009). It would therefore be anticipated that aerosolized delivery of B. pseudomallei would lower the dose required to establish disease in a host, relative to the i.n. route. The $\mathrm{LD}_{50}$ values presented in Table 2 reveal that aerosol delivery of $B$. pseudomallei enhances the disease potential of strain 1026b 99-fold in BALB/c mice, whereas no change in the disease potential of strain DD503 is observed in BALB/C mice relative to i.n. delivery. Similarly, KWH infection of C57BL/6 mice is enhanced 15-fold and K96243 infection of BALB/c mice is enhanced 46-fold when organisms are aerosolized rather than delivered i.n.. The variation in the overall effectiveness of aerosol delivery over i.n. delivery could be attributed to the variation of apparatus design and operation in different laboratories (particle size, whole body versus nose only, or flow rate). Therefore, aerosol delivery of $B$. pseudomallei may reduce the number of organisms required to establish disease, but this methodology must be optimized in each laboratory.

Respiratory infections mediated by aerosolization of B. pseudomallei result primarily in colonization of the lung, with reduced colonization of the liver and spleen as observed for the i.n. model (Jeddeloh et al., 2003; Lever et al., 2009). Additional host sites are colonized including blood and the kidneys, but importantly the brain was also shown to be colonized with significant numbers of B. pseudomallei (Lever et al., 2009). Like the i.n. route of infection, aerosol delivery of B. pseudomallei results in both upper and lower respiratory tract infections but without the involvement of the digestive system. Thus, meningitis resulting from aerosol delivery is likely due to upper respiratory tract colonization leading to invasion the olfactory bulbs. As reported for the i.n. model, aerosol infections result in confounding meningitis and potential NALT-related dissemination to other organs.

The mouse upper respiratory tract anatomy differs from that of a human with respect to the relative size and the more significant use of the upper respiratory tract for olfactory purposes. Normalization of the average nasal cavity surface area of the mouse and human (Reznik, 1990) against the total lung capacity of each (Hoyt et al., 2007) reveals that the mouse has a relative nasal cavity surface area of greater than 100-fold that of a human. Given the propensity for $B$. pseudomallei to colonize the mouse upper respiratory tract, and the over-represented surface area of the mouse nasal cavity, both i.n. and aerosol routes of infection will likely lead to mixed dissemination pathways involving the expected lower respiratory tract dissemination as well as over-represented upper respiratory tract dissemination. Furthermore, infections secondary to pneumonia may also present as a result of upper respiratory tract colonization, including meningitis, otitis media, and rhinitis. These caveats must be addressed when interpreting findings from aerosol and i.n. infection models that focus on the systemic disease resulting from respiratory tract dissemination.

\section{Intratracheal and oral models}

Intratracheal (i.t.) instillations have not been used to model respiratory melioidosis in the mouse, though they have been described in the rat model as discussed below. A potential benefit of the i.t. model is the direct delivery of organisms to the lung for the purposes of modeling pulmonary disease with minimal involvement of the upper respiratory tract. A surgical method of i.t. infection of mice involves an incision to the ventral neck skin to expose the trachea, injection of a bacterial suspension by needle through the tracheal wall, followed by application of a surgical staple. This method has been successfully used to enhance delivery of organisms specifically to the lung for several bacterial respiratory pathogens, including Legionella pneumophila (Brieland et al., 1994), Haemophilus influenza (Heitmann et al., 1999), Pseudomonas aeruginosa (Moser et al., 1997), Klebsiella pneumoniae (Fan et al., 2002), and Burkholderia cepacia (Chiu et al., 2001). More recently, non-surgical variations of i.t. infections have been reported as an additional enhancement to surgical i.t. infections which avoid the trauma associated with surgery (Su et al., 2004; Lacher et al., 2010). The future use of non-surgical i.t. instillation may provide the ability to study pulmonary melioidosis and lung-specific dissemination in the absence of the confounding involvement of the upper respiratory tract.

The investigation of oral infection was reported as part of a study by Barnes et al. which compared five different routes of infection for both BALB/c and C57BL/6 mice, using two strains of B. pseudomallei. The method of oral instillation reported in the study involved deposition of an infectious dose to the back of the throat (Barnes and Ketheesan, 2005). This method of infection has been reported by others as a transoral infection methodology affecting both the lung and stomach as a result of both ingestion and inhalation of the inoculum (Lacher et al., 2010). The transoral $\mathrm{LD}_{50}$ values were higher than those identified for i.n. infection (Barnes 
and Ketheesan, 2005), and given the lung involvement of transoral infections, the stomach would appear to be less susceptible to infection than the lung. A more recent study demonstrated a direct esophageal delivery of B. pseudomalle $i$ into BALB/c and C57BL/6 mice results in oral $\mathrm{LD}_{50}$ values of greater than $7 \times 10^{8} \mathrm{CFU}$ (West et al., 2010). These results suggest that mice are not susceptible to melioidosis by ingestion, which is consistent with evidence that human susceptibility to orally transmitted B. pseudomallei is not common (Inglis et al., 2000a).

\section{CHRONIC MOUSE MODELS}

Characterizations of mouse susceptibility to $B$. pseudomallei infection identified a high susceptibility of BALB/c mice whereas C57BL/6 are thought to be relatively resistant (Leakey et al., 1998). This differential susceptibility to infection was used to classify $\mathrm{BALB} / \mathrm{c}$ as an acute model whereas $\mathrm{C} 57 \mathrm{BL} / 6$ challenge was thought to represent a model of chronic disease. Chronic clinical melioidosis is characterized by prolonged duration of the disease identified by evidence of persistence and relapse, and in endemic Thailand relapse typically occurs an average of 26 weeks following initial presentation (Limmathurotsakul et al., 2006). Unique incidents of relapse of 29 and 62 years post-infection have also been reported in humans (Chodimella et al., 1997; Ngauy et al., 2005).

The majority of murine melioidosis models published thus far have focused on characterization of acute disease occurring within the first several weeks of infection, with the exception of s.c. infections which may proceed beyond 6 weeks (Steward et al., 2005). TO mice are similarly resistant to melioidosis as C57BL/6, and an early study evaluating chronic persistence of B. pseudomallei in a low dose, i.p. TO mouse model found sterilizing clearance of bacteria from the spleen 4 weeks post-infection and non-quantifiable trace colonization of the liver (Santanirand et al., 1999). A more recent study found that low dose i.p. infection of BALB/c mice resulted in undetectable bacterial persistence beyond 5 days post-infection, using both PCR and culture techniques, with monitoring out to 4 weeks (Srisurat et al., 2010). These findings suggest that mice surviving challenge with $B$. pseudomallei effectively clear bacteria by 4 weeks post-infection by the i.p. route with a low likelihood of chronic persistence.

Additional studies are required to evaluate the potential for a reproducibly chronic mouse model of melioidosis, with persistence more closely mirroring the clinical reports. Resistant mouse strains such as TO and C57BL/6 mice may offer the best potential for developing a chronic disease state, and the prolonged course of the disease of the s.c. route of infection may lend itself to establishing a chronic persistence.

\section{HOST RESPONSE TO INFECTION}

The host cytokine responses detected during murine melioidosis indicate that $B$. pseudomallei elicits a strong proinflammatory response, paralleling what is observed in clinical melioidosis. Initial investigations characterizing the host response in murine melioidosis sought to define potential differences in the host response to melioidosis in different mouse strains. It has long been known that C57BL/6 mice are less susceptible to melioidosis than other mouse strains such as BALB/c, and it was initially hypothesized that differential susceptibility may be due to a variation in the
Th1/Th2 balance. An investigation of the IgG subtypes produced during disease indicated that C57BL/6 mice have a much higher relative IgG2a response than $\mathrm{BALB} / \mathrm{c}$ mice, suggestive of a stronger Th1 response in the resistant C57BL/6 mice (Hoppe et al., 1999). Subsequent studies revealed that BALB/c mice were not deficient in production of proinflammatory Th1-type cytokines, and in fact produced much higher levels of such cytokines (TNF- $\alpha$, IL-6, and IL-1 $\beta$ ) than C57BL/6 mice (Ulett et al., 2000), arguing against proinflammatory deficiencies in the BALB/c melioidosis model. The preferentially elevated proinflammatory cytokine response in BALB/c mice has also been confirmed using different bacterial strains (Ulett et al., 2002) and routes of infection (Liu et al., 2002).

The strength of the proinflammatory response in BALB/c mice was implicated in contributing to the acute disease by potential toxic effects of high cytokine levels, although the possibility remains that elevated proinflammatory cytokines are indicators rather than contributors to fatal disease (Ulett et al., 2000). Given the important role of proinflammatory cytokines in managing disease, it is difficult to address whether excessive levels of proinflammatory cytokines contribute to morbidity. Partial neutralization of IFN- $\gamma$ by antibody depletion studies support the hypothesis that elevated proinflammatory cytokines do not themselves participate in morbidity in the mouse model, as depletion of IFN- $\gamma$ results in a drastic increase in susceptibility to infection rather than protection from potential toxic effects (Santanirand et al., 1999). Caspase-1 knockout mice, which produced reduced levels of IFN- $\gamma$, are also more susceptible to melioidosis (Breitbach et al., 2009). Additionally, supplementation with IFN- $\gamma$ in combination with low dose ceftazidime increased the survival of $B$. pseudomallei-infected BALB/c mice, suggesting that the proinflammatory response of $\mathrm{BALB} / \mathrm{c}$ to $B$. pseudomalle $i$ is not itself contributing to morbidity (Propst et al., 2010). The critical role of IFN- $\gamma$ in controlling melioidosis is shared by additional proinflammatory cytokines and host systems. Mutation or depletion of IL-12p35, IL-12p40, and IL-18 increases the susceptibility of mice to challenge with $B$. pseudomallei, as does depletion of mature T cells (Haque et al., 2006). Defining the optimal IFN- $\gamma$ concentration may help to address the role of IFN- $\gamma$ in melioidosis, and address issues regarding potential therapeutic use of IFN- $\gamma$ in treating melioidosis (Koh and Limmathurotsakul, 2010).

\section{CLINICAL RELEVANCE OF MOUSE MODELS}

Mice represent an excellent surrogate for the study of clinical melioidosis given the similarity in the: (i) susceptibility to infection by multiple routes of infection, (ii) proinflammatory response to infection, and (iii) involvement of similar target organs. The lung, liver, and spleen are the primary sites of infection for both clinical and murine melioidosis as assessed by computerized tomography (CT) and/or culture. While experimental murine melioidosis models allow for a quantitative analysis of bacterial burden in these organs by culture, little is known about clinical bacterial burdens given that diagnostic CT imaging of melioidosis provides qualitative pathological analyses. Future developments in clinical diagnostic imaging tools may facilitate quantitative comparisons of clinical bacterial burdens to the mouse model. Similarly, developments of diagnostic imaging in the mouse may reveal clinically relevant pathology, including the stereotypical "honeycomb" liver abscesses associated with melioidosis (Lim and Chong, 2010). 


\section{ADDITIONAL ANIMAL MODELS \\ HAMSTER}

Hamster models of melioidosis are typically associated with a rapidly fatal acute disease. The intraperitoneal method of infection has been frequently used to identify critical $B$. pseudomallei virulence determinants in the Golden Syrian hamster model where wild type B. pseudomallei strains typically have 2 day $\mathrm{LD}_{50}$ values of fewer than 10 organisms (Table 3 ). This is in contrast with the mouse i.p. model where the $1026 \mathrm{~b}$ strain, studied in both models, has an $\mathrm{LD}_{50}$ of $10^{4}$ organisms in BALB/c mice (Wikraiphat et al., 2009), suggesting that hamsters are $10^{3}$-fold more sensitive to systemic infections than the mouse. Thus, investigation of B. pseudomallei virulence determinant mutant attenuation in the hyper-sensitive hamster model results in convincing demonstration of the importance of certain genetic loci given the susceptibility of these animals to melioidosis.

The s.c. and aerosol routes of infection have also been used to model melioidosis in the hamster model, but given the extreme sensitivity of hamsters to infection, the small differences in $\mathrm{LD}_{50}$

Table 3 | Other animal infection models.

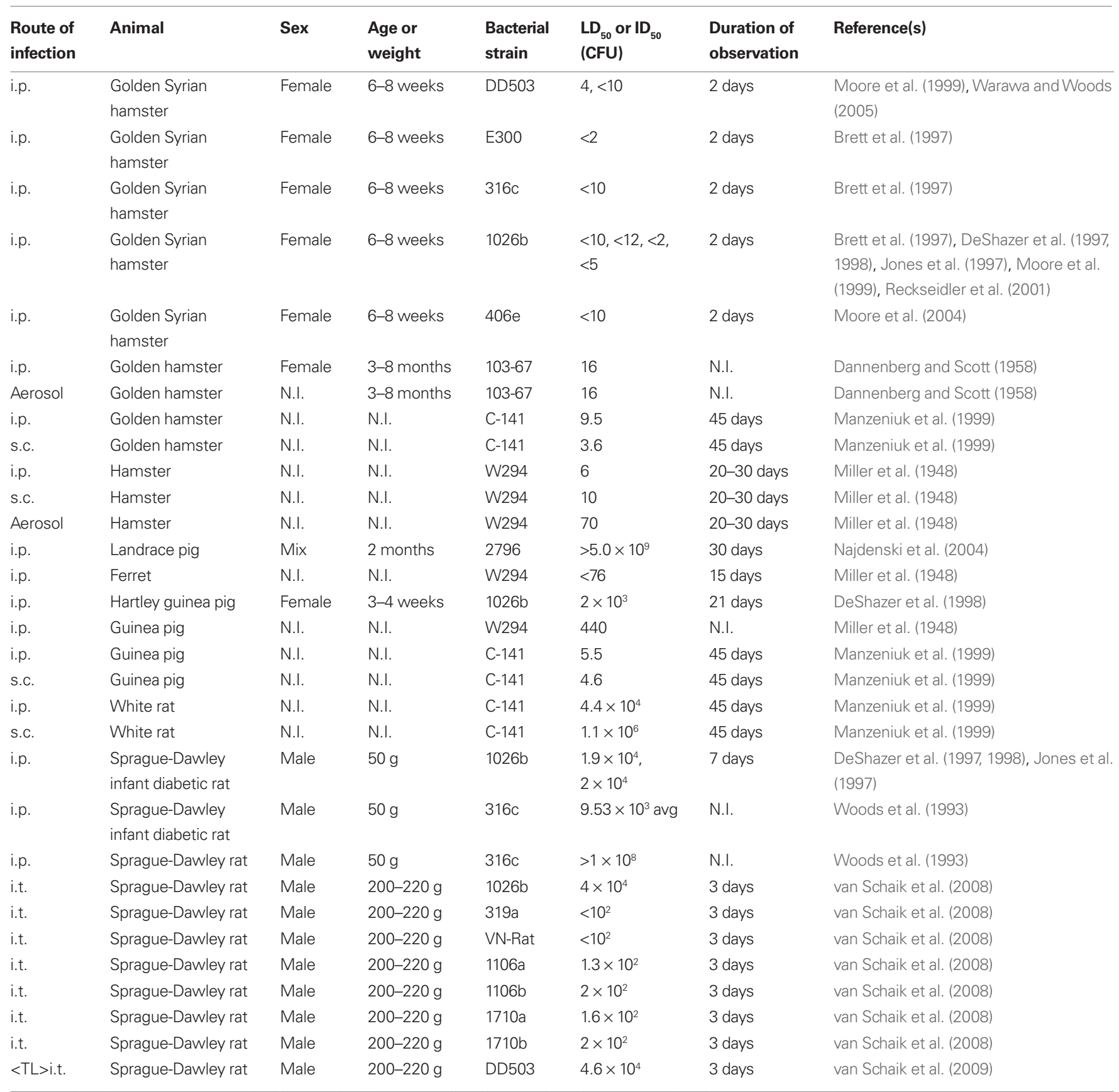

i.p., Intraperitoneal; s.c., subcutaneous; i.t., intratracheal; N.I., not indicated. 
identified for alternate routes of infection do not permit conclusions about varied susceptibility of hamsters based on the route of infection. Aerosol delivery of strain 103-67 did not result in an altered $\mathrm{LD}_{50}$ relative to i.p. infection, however a similar study using strain W294 identified a 12-fold decrease in virulence by aerosol delivery (Table 3). Future studies may be required to define the susceptibility of hamsters to respiratory disease.

\section{RAT}

Rat models of melioidosis have primarily focused on i.p. or i.t. infection methods, modeling septicemic and respiratory diseases, respectively. Initial studies describing the i.p. route of infection of Sprague-Dawley rats found that infant rats were resistant to B. pseudomallei challenge of more than $10^{9}$ organisms, however streptozotocin-induced diabetes increased infant rat susceptibility by over $10^{5}$-fold (Woods et al., 1993). Thus, the infant diabetic rat model offers the potential to investigate the clinically important role of diabetes in an animal model. Non-diabetic Sprague-Dawley rats are relatively resistant to i.p. infection but are acutely susceptible to respiratory infection by the intratracheal route with $\mathrm{LD}_{50}$ values ranging from $<10^{2}$ to $4.0 \times 10^{4} \mathrm{CFU}$ (van Schaik et al., 2008). These findings suggest that the rat has a higher resistance to respiratory melioidosis than mice, whereby i.t. infections of rats require 30to 40 -fold more organisms to establish disease than i.n. delivery of the same B. pseudomallei 1026b and DD503 strains in BALB/C mice (Tables 2 and 3 ).

A chronic pulmonary melioidosis rat model has also been developed which involves suspension of B. pseudomallei in agar beads before surgical intratracheal instillation to the lung. This model permits long term colonization of the lung with peak lung colonization at approximately 1 week post-infection, and chronic infections extending beyond 2 weeks. This model was developed using B. pseudomallei strain 1026b, which has a similar $\mathrm{LD}_{50}$ value by agar bead delivery as by delivery in PBS suspension (van Schaik et al., 2008). Thus, agar bead delivery of B. pseudomallei does not affect the overall virulence of the bacteria, but allows for a controlled establishment of a long term chronic infection using sub-lethal doses of B. pseudomallei.

Commercially available tools for studying the immunology of the rat are limited in comparison to the mouse model. Excellent developments have been made in the study of melioidosis in the rat including intratracheally introduced pulmonary disease, chronic disease establishment and diabetes modeling. Future efforts may similarly translate these methods to the mouse model to permit access to the analytical tools required to investigate the host immune response in detail.

\section{OTHER MAMMALIAN MODELS}

An important 1948 study by Miller et al. reported on the susceptibility of a wide range of laboratory animals to infection with B. pseudomallei (Miller et al., 1948). The authors infected numerous animal species by a variety of routes of infection, including i.v., i.p., s.c., and aerosol, and concluded that hamsters and ferrets represent the most susceptible melioidosis animal models, guinea pigs and rabbits were moderately susceptible, while mice, rats, and non-human primates were only slightly susceptible to infection. Approximately half of these species have been developed into current day melioidosis animal models, and there is now a renewed interest in developing non-human primate models given the potential translational relevance to clinical melioidosis. The Miller et al. study found that a rhesus macaque infected s.c. with $1.5 \times 10^{6} \mathrm{CFU}$ of B. pseudomallei developed transient subcutaneous abscesses which healed within 2 weeks, and 2 months postinfection, no organisms were found in host tissues (Miller et al., 1948). A more recent study found that Hamadryas baboons are susceptible to melioidosis by i.p. and s.c. routes of infection with a rapid disease involving lungs, liver, spleen, and lymph nodes (Manzeniuk et al., 1999). Consistent with the varying susceptibility of mouse strains to melioidosis, a range of susceptibility is observed amongst non-human primate species, as is the case for the extreme susceptibility of gorillas to melioidosis (Yap et al., 1995). Studies are ongoing to identify non-human primate models suitable for modeling clinical disease, with a focus on respiratory disease models.

The naturally occurring infection of livestock animals has been recently modeled in the laboratory for pigs. Pigs are considered to be moderately to highly resistant to infection relative to other livestock species (Choy et al., 2000). Consistent with these observations, experimental infection of Landrace pigs with a high-dose i.v. infection $\left(5.0 \times 10^{9} \mathrm{CFU}\right)$ failed to elicit a symptomatic infection. Bacteria were cultured from the lung, liver, spleen, and mesenterial lymph nodes with immediate clearance initiated from day 1 with the exception of lung which peaked in colonization at day 3 (Najdenski et al., 2004). These findings suggest that pigs may be more susceptible to respiratory rather than systemic disease.

\section{INVERTEBRATE MODELS}

Numerous pathogenic organisms are transmitted by insect vector, and the significant host range of $B$. pseudomallei suggests that insects may also be susceptible to melioidosis and/or vectors of disease. Xenopsylla cheopis fleas and Aëdes aegypti mosquitoes have been used to study the transmission of $B$. pseudomallei to guinea pigs (Blanc and Baltazard, 1949). Both fleas and mosquitoes were demonstrated to be able to acquire infection from a $B$. pseudomallei-infected guinea pig and in turn transmit disease to naïve guinea pigs. The role of fleas and mosquitoes as vectors for transmitting melioidosis has not been further investigated in the laboratory, however, an investigation of bacterial species naturally carried by syanthropic flies in Malaysia found that of the four fly species trapped, all four were carriers of B. pseudomallei, with Chrysomya megacephala representing the most frequent carrier (Sulaiman et al., 2000). Another investigation of B. pseudomallei transmission by ticks revealed that infected rabbits could transmit infection to the tick species Rhipicephalus bursa and Haemaphysalis punctata and that B. pseudomallei was successfully collected from the tick feces (Kharbov et al., 1981). Given the range of animal species susceptible to infection by $B$. pseudomallei, it is not unexpected that insects could be carriers of melioidosis. However, the role of insects as natural transmission vectors has not been well studied, likely due to the ease with which $B$. pseudomallei may be cultured directly from the environment. Studies of insect carriage of B. pseudomallei may provide insights into their possible role as vectors of disease. 
Various organisms found in tropical soils such as ameba, nematode worms, and germinating fungal spores may be opportunistically infected by $B$. pseudomallei, and as such, these interactions have been modeled in the laboratory. Acanthamoeba species can be infected by $B$. pseudomallei, and may represent an ecological interaction (Inglis et al., 2000b). Acanthamoeba have also been used to demonstrate a potential role for flagella in B. pseudomallei invasion of eukaryotic cells (Inglis et al., 2003). Interactions of B. pseudomalle $i$ with nematodes, naturally found in the soil, results in a rapid death of nematodes at a 50\% lethality achieved within 16-23 h (O'Quinn et al., 2001). Germinating fungal Gigaspora decipiens spores are another potential species that may be opportunistically infected in the environment, and have also been shown to be susceptible to colonization by B. pseudomallei in the laboratory (Levy et al., 2003). B. pseudomallei apparently do not require a host for persistence in the environment, but may opportunistically infect small soil organisms during its life cycle in tropical soils as a method for increasing in titer.

\section{REFERENCES}

Abbink, F. C., Orendi, J. M., and de Beaufort, A. J. (2001). Mother-tochild transmission of Burkholderia pseudomallei. N. Engl. J. Med. 344, 1171-1172.

Atkins, T., Prior, R. G., Mack, K., Russell, P., Nelson, M., Oyston, P. C., Dougan, G., and Titball, R.W. (2002). A mutant of Burkholderia pseudomallei, auxotrophic in the branched chain amino acid biosynthetic pathway, is attenuated and protective in a murine model of melioidosis. Infect. Immun. 70, 5290-5294.

Barnes, J. L., and Ketheesan, N. (2005). Route of infection in melioidosis. Emerging Infect. Dis. 11, 638-639.

Blanc, G., and Baltazard, M. (1949). Recherches sur la melioidose infection a bacille de Whitmore - etude experimentale. Arch. Inst. Pasteur Maroc 3, 520-584.

Breitbach, K., Sun, G. W., Kohler, J., Eske, K., Wongprompitak, P., Tan, G., Liu, Y., Gan, Y. H., and Steinmetz, I. (2009). Caspase-1 mediates resistance in murine melioidosis. Infect. Immun. 77, 1589-1595.

Brett, P. J., Deshazer, D., and Woods, D. E. (1997). Characterization of Burkholderia pseudomallei and Burkholderiapseudomallei-like strains. Epidemiol. Infect. 118, 137-148.

Brieland, J., Freeman, P., Kunkel, R., Chrisp, C., Hurley, M., Fantone, J., and Engleberg, C. (1994). Replicative Legionella pneumophila lung infection in intratracheally inoculated A/J mice. A murine model of human Legionnaires' disease. Am. J. Pathol. 145, 1537-1546.

Brown, A. E., Dance, D. A., Suputtamongkol, Y., Chaowagul,
W., Kongchareon, S., Webster, H. K., and White, N. J. (1991). Immune cell activation in melioidosis: increased serum levels of interferon-gamma and soluble interleukin-2 receptors without change in soluble CD8 protein. J. Infect. Dis. 163, 1145-1148.

Chadwick, D. R., Ang, B., Sitoh, Y. Y., and Lee, C. C. (2002). Cerebral melioidosis in Singapore: a review of five cases. Trans. R. Soc. Trop. Med. Hyg. 96, 72-76.

Chaowagul, W., White, N. J., Dance, D. A., Wattanagoon, Y., Naigowit, P., Davis, T. M., Looareesuwan, S., and Pitakwatchara, N. (1989). Melioidosis: a major cause of community-acquired septicemia in northeastern Thailand. J. Infect. Dis. 159, 890-899.

Cheng, A. C., and Currie, B. J. (2005). Melioidosis: epidemiology, pathophysiology, and management. Clin.

Chetchotisakd, P., Anunnatsiri, S., Kiatchoosakun, S., and Kularbkaew, C. (2010). Melioidosis pericarditis mimicking tuberculous pericarditis. Clin. Infect. Dis. 51, e46-e49.

Chiu, C. H., Ostry, A., and Speert, D. P. (2001). Invasion of murine respiratory epithelial cells in vivo by Burkholderia cepacia. J. Med. Microbiol. 50, 594-601.

Chodimella, U., Hoppes, W. L., Whalen, S., Ognibene, A. J., and Rutecki, G. W. (1997). Septicemia and suppuration in a Vietnam veteran. Hosp. Pract. (Off. Ed.) 32, 219-221.

Choy, J. L., Mayo, M., Janmaat, A., and Currie, B. J. (2000). Animal melioidosis in Australia. Acta Trop. 74, 153-158. Flagella are virulence determinants Microbiol. Rev. 18, 383-416.

Chua,K.L.,Chan,Y.Y., andGan,Y.H.(2003).

\section{CONCLUDING REMARKS}

Numerous interactions of $B$. pseudomallei and animal species have been modeled in the laboratory, though none to the extent of the interaction with the mouse. Murine melioidosis shares a great number of similarities with clinical melioidosis with respect to disease presentation and immune response. The recent focus of biodefense-related modeling of respiratory disease in mice has demonstrated that mice are excellent surrogate models for studying B. pseudomallei pulmonary disease, but that the use of mice to specifically model disease acquisition may pose problems due to major differences in the upper respiratory tract anatomy between mice and humans. Intratracheal instillations may provide an alternative infection strategy to study respiratory disease in mice, and future developments using aerosol infections of non-human primates may provide excellent models of biodefense-related disease acquisition. Given the wealth of tools available to study host immunology in the mouse, the availability of subject animals to work with, the similarity in human and murine melioidosis, and the affordability of mouse studies, the mouse represents an excellent model for both pulmonary and septicemic melioidosis.

of Burkholderia pseudomallei. Infect. Immun. 71, 1622-1629.

Currie, B. J., Fisher, D. A., Howard, D. M., and Burrow, J. N. (2000a). Neurological melioidosis. Acta Trop. 74, 145-151.

Currie, B. J., Fisher, D. A., Howard, D. M., Burrow, J. N., Lo, D., Selva-Nayagam, S., Anstey, N. M., Huffam, S. E., Snelling, P. L., Marks, P. J., Stephens, D. P., Lum, G. D., Jacups, S. P., and Krause, V.L. (2000b). Endemic melioidosis in tropical northern Australia: a 10-year prospective study and review of the literature. Clin. Infect. Dis. 31, 981-986.

Currie, B. J., Fisher, D. A., Howard, D. M., Burrow, J. N., Selvanayagam, S., Snelling, P. L., Anstey, N. M., and Mayo, M.J.(2000c). The epidemiology of melioidosis in Australia and Papua New Guinea. Acta Trop. 74, 121-127.

Dannenberg, A. M. Jr., and Scott, E. M. (1958). Melioidosis: pathogenesis and immunity in mice and hamsters. Studies, I. with virulent strains of Malleomycespseudomallei.J. Exp. Med. 107, 153-166.

Derbyshire, J. B. (2002). The eradication of glanders in Canada. Can. Vet. J. 43, 722-726.

DeShazer, D., Brett, P. J., Carlyon, R., and Woods, D. E. (1997). Mutagenesis of Burkholderia pseudomallei with Tn5OT182: isolation of motility mutants and molecular characterization of the flagellin structural gene. J. Bacteriol. 179, 2116-2125.

DeShazer, D., Brett, P. J., and Woods, D. E. (1998). The type II O-antigenic polysaccharide moiety of Burkholderia pseudomallei lipopolysaccharide is required for serum resistance and virulence. Mol. Microbiol. 30, 1081-1100.
Fan, M. H., Klein, R. D., Steinstraesser, L., Merry, A. C., Nemzek, J.A., Remick, D. G., Wang, S. C., and Su, G. L. (2002). An essential role for lipopolysaccharide-binding protein in pulmonary innate immune responses. Shock 18, 248-254.

Fisher, M. W., Hillegas, A. B., and Nazeeri, P. L. (1971). Susceptibility in vitro and in vivo of Pseudomonas pseudomallei to rifampin and tetracyclines. Appl. Microbiol. 22, 13-16.

Friedland, J. S., Suputtamongkol, Y., Remick, D. G., Chaowagul,W., Strieter, R. M., Kunkel, S. L., White, N. J., and Griffin, G. E. (1992). Prolonged elevation of interleukin- 8 and interleukin- 6 concentrations in plasma and of leukocyte interleukin-8 mRNA levels during septicemic and localized Pseudomonas pseudomallei infection. Infect. Immun. 60, 2402-2408.

Goodyear, A., Kellihan, L., BielefeldtOhmann, H., Troyer, R., Propst, K., and Dow, S. (2009). Protection from pneumonic infection with Burkholderia species by inhalational immunotherapy. Infect. Immun. 77, 1579-1588.

Haque, A., Easton, A., Smith, D., O'Garra Van, A., Rooijen, N., Lertmemongkolchai, G., Titball, R. W., and Bancroft, G. J. (2006). Role of $\mathrm{T}$ cells in innate and adaptive immunity against murine Burkholderia pseudomallei infection. J. Infect. Dis. 193, 370-379.

Harland, D. N., Chu, K., Haque, A., Nelson, M., Walker, N. J., Sarkar-Tyson, M. Atkins, T. P., Moore, B., Brown, K. A., Bancroft, G., Titball, R. W., and Atkins, H. S. (2007). Identification of a LolC homologue in Burkholderiapseudomal$l e i$, a novel protective antigen for melioidosis. Infect. Immun. 75, 4173-4180. 
Heitmann, S., Tschernig, T., Larbig, M., Steinmetz, I., Hedrich, H. J., and Pabst, R. (1999). Immunohistological characterization of leukocytes in the lungs of healthy mice and after bacterial intratracheal infection. Lab. Anim. $33,288-294$.

Hicks, C. L., Kinoshita, R., and Ladds, P. W. (2000). Pathology of melioidosis in captive marine mammals. Aust. Vet. J. 78, 193-195.

Hoppe, I., Brenneke, B., Rohde, M., Kreft, A., Haussler, S., Reganzerowski, A., and Steinmetz, I. (1999). Characterization of a murine model of melioidosis: comparison of different strains of mice. Infect. Immun. 67, 2891-2900.

Hoyt, R. F. J., Hawkins, J. V., St. Clair, M. B., and Kennet, M. B. (2007). "Mouse physiology", in The Mouse in Biomedical Research, eds J. G. Fox, S. W. Barthold, M. T. Davisson, C. E. Newcomer, F. W. Quimby, and A. L. Smith (Burlington, MA: Academic Press), 23-90.

Inglis, T. J., Garrow, S. C., Henderson, M., Clair, A., Sampson, J., O'Reilly, L., and Cameron, B. (2000a). Burkholderia pseudomallei traced to water treatment plant in Australia. Emerging Infect. Dis. 6, 56-59.

Inglis, T. J., Rigby, P., Robertson, T. A., Dutton, N. S., Henderson, M., and Chang, B. J. (2000b). Interaction between Burkholderia pseudomallei and Acanthamoeba species results in coiling phagocytosis, endamebic bacterial survival, and escape. Infect. Immun. 68, 1681-1686.

Inglis, T. J., Robertson, T., Woods, D. E., Dutton, N., and Chang, B. J. (2003). Flagellum-mediated adhesion by Burkholderia pseudomallei precedes invasion of Acanthamoeba astronyxis. Infect. Immun. 71, 2280-2282.

Jeddeloh, J. A., Fritz, D. L., Waag, D. M., Hartings, J. M., and Andrews, G. P. (2003). Biodefense-driven murine model of pneumonic melioidosis. Infect. Immun. 71, 584-587.

Jones, A. L., DeShazer, D., and Woods, D. E. (1997). Identification and characterization of a two-component regulatory system involved in invasion of eukaryotic cells and heavy-metal resistance in Burkholderia pseudomallei. Infect. Immun. 65, 4972-4977.

Kaestli, M., Mayo, M., Harrington, G., Ward, L., Watt, F., Hill, J. V., Cheng, A. C., and Currie, B. J. (2009). Landscape changes influence the occurrence of the melioidosis bacterium Burkholderia pseudomallei in soil in Northern Australia. PLoS Negl. Trop. Dis. 3, e364. doi: 10.1371/journal. pntd.0000364.

Kharbov, D., Velianov, D., and Raucheva, T. (1981). Ecological aspects of Pseudomonaspseudomallei interactions with Ixodid ticks. Acta Microbiol. Bulg. 8, 17-24.

Kim, C. S., and Hu, S. C. (1998). Regional deposition of inhaled particles in human lungs: comparison between men and women. J. Appl. Physiol. 84, 1834-1844.

Koh, G. C., and Limmathurotsakul, D. (2010). Gamma interferon supplementation for melioidosis. Antimicrob. Agents Chemother. 54, 4520; author reply $4520-4521$.

Lacher, S. E., Johnson, C., Jessop, F., Holian, A., and Migliaccio, C. T. (2010). Murine pulmonary inflammation model: a comparative study of anesthesia and instillation methods. Inhal. Toxicol. 22, 77-83.

Laopaiboon, V., Chamadol, N., Buttham, H., and Sukeepaisarnjareon, W. (2009).CT findings of liver and splenic abscesses in melioidosis: comparison with those in non-melioidosis. J. Med. Assoc. Thai. 92, 1476-1484.

Lauw, F. N., Simpson, A. J., Prins, J. M., Smith, M. D., Kurimoto, M., van Deventer, S. J., Speelman, P., Chaowagul, W., White, N. J., and van der Poll, T. (1999). Elevated plasma concentrations of interferon (IFN)gamma and the IFN-gamma-inducing cytokines interleukin (IL)-18, IL-12, and IL-15 in severe melioidosis. J. Infect. Dis. 180, 1878-1885.

Lauw, F. N., Simpson, A. J., Prins, J. M., van Deventer, S. J., Chaowagul, W., White, N. J., and van der Poll, T. (2000). The CXC chemokines gamma interferon (IFN-gamma)-inducible protein 10 and monokine induced by IFN-gamma are released during severe melioidosis. Infect. Immun. 68, 3888-3893.

Leakey, A. K., Ulett, G. C., and Hirst, R. G. (1998). BALB/c and C57Bl/6 mice infected with virulent Burkholderia pseudomallei provide contrasting animal models for the acute and chronic forms of human melioidosis. Microb. Pathog. 24, 269-275.

Leelarasamee, A. (1998). Burkholderia pseudomallei: the unbeatable foe? Southeast Asian J. Trop. Med. Public Health 29, 410-415.

Lever, M. S., Nelson, M., Stagg, A. J., Beedham, R. J., and Simpson, A. J. (2009). Experimental acute respiratory Burkholderia pseudomallei infection in BALB/c mice. Int. J. Exp. Pathol. 90, 16-25.

Levy, A., Chang, B. J., Abbott, L. K., Kuo, J., Harnett, G., and Inglis, T. J. (2003). Invasion of spores of the arbuscular mycorrhizal fungus Gigaspora decipiens by Burkholderia spp. Appl. Environ. Microbiol. 69, 6250-6256.

Lim, K. S., and Chong, V. H. (2010). Radiological manifestations of melioidosis. Clin. Radiol. 65, 66-72.
Limmathurotsakul, D., Chaowagul, W., Chierakul, W., Stepniewska, K., Maharjan, B., Wuthiekanun, V., White, N. J., Day, N. P., and Peacock, S. J. (2006). Risk factors for recurrent melioidosis in northeast Thailand. Clin. Infect. Dis. 43, 979-986.

Limmathurotsakul, D., Wongratanacheewin, S., Teerawattanasook, N., Wongsuvan, G., Chaisuksant, S., Chetchotisakd, P., Chaowagul, W., Day, N. P., and Peacock, S. J. (2010a). Increasing incidence of human melioidosis in Northeast Thailand. Am. J. Trop. Med. Hyg. 82, 1113-1117.

Limmathurotsakul, D., Wuthiekanun, V., Chantratita, N., Wongsuvan, G., Amornchai, P., Day, N.P., and Peacock, S. J. (2010b). Burkholderia pseudomallei is spatially distributed in soil in northeast Thailand. PLoS Negl. Trop. Dis. 4, e694. doi: 10.1371/journal. pntd.0000694.

Liu, B., Koo, G. C., Yap, E. H., Chua, K. L., and Gan, Y. H. (2002). Model of differential susceptibility to mucosal Burkholderia pseudomallei infection. Infect. Immun. 70, 504-511.

Manzeniuk, I.N., Galina, E.A., Dorokhin, V. V., Kalachev, I., Borzenkov, V. N., and Svetoch, E. A. (1999). Burkholderia mallei and Burkholderia pseudomallei. Study of immunoand pathogenesis of glanders and melioidosis. Heterologous vaccines. Antibiot. Khimioter 44, 21-26.

McCormick, J. B., Sexton, D. J., McMurray, J. G., Carey, E., Hayes, P., and Feldman, R. A. (1975). Human-to-human transmission of Pseudomonas pseudomallei. Ann. Intern. Med. 83, 512-513.

Miller, W. R., Pannell, L., Cravitz, L., Tanner, W. A., and Rosebury, T. (1948). Studies on certain biological characteristics of Malleomyces mallei and Malleomyces pseudomallei. IVirulence, I. and infectivity for animals. J. Bacteriol. 55, 127-135.

Moore, R. A., DeShazer, D., Reckseidler, S., Weissman, A., and Woods, D.E. (1999). Efflux-mediated aminoglycoside and macrolide resistance in Burkholderia pseudomallei. Antimicrob. Agents Chemother. 43, 465-470.

Moore, R. A., Reckseidler-Zenteno, S., Kim, H., Nierman, W., Yu, Y., Tuanyok, A., Warawa, J., DeShazer, D., and Woods, D. E. (2004). Contribution of gene loss to the pathogenic evolution of Burkholderiapseudomallei and Burkholderia mallei.Infect.Immun. 72, 4172-4187.

Morse, L. P., Moller, C. C., Harvey, E., Ward, L., Cheng, A. C., Carson, P. J., and Currie, B. J. (2009). Prostatic abscess due to Burkholderia pseudomallei: 81 cases from a 19-year prospective melioidosis study. J. Urol. 182, 542-547; discussion 547.

Moser, C., Johansen, H. K., Song, Z., Hougen, H. P., Rygaard, J., and Hoiby, N. (1997). Chronic Pseudomonas aeruginosa lung infection is more severe in Th2 responding BALB/c mice compared to Thl responding $\mathrm{C} 3 \mathrm{H} / \mathrm{HeN}$ mice. APMIS 105, 838-842.

Muttarak, M., Peh, W.C., Euathrongchit, J., Lin, S.E., Tan, A. G., Lerttumnongtum, P., and Sivasomboon, C. (2008). Spectrum of imaging findings in melioidosis. Br. J. Radiol. 82, 514-521.

Najdenski, H., Kussovski, V., and Vesselinova, A. (2004). Experimental Burkholderia pseudomallei infection of pigs. J. Vet. Med. B Infect. Dis. Vet. Public Health 51, 225-230.

Nelson, M., Prior, J. L., Lever, M. S., Jones, H. E., Atkins, T. P., and Titball, R. W. (2004). Evaluation of lipopolysaccharide and capsular polysaccharide as subunit vaccines against experimental melioidosis. J. Med. Microbiol. 53, 1177-1182.

Ngauy, V., Lemeshev, Y., Sadkowski, L., and Crawford, G. (2005). Cutaneous melioidosis in a man who was taken as a prisoner of war by the Japanese during World War II. J. Clin. Microbiol. 43, 970-972.

Nierman, W. C., DeShazer, D., Kim, H. S., Tettelin, H., Nelson, K.E., Feldblyum, T., Ulrich, R. L., Ronning, C. M., Brinkac, L.M., Daugherty, S.C., Davidsen, T.D., Deboy, R. T., Dimitrov, G., Dodson, R. J., Durkin, A. S., Gwinn, M. L., Haft, D. H., Khouri, H., Kolonay, J. F., Madupu, R., Mohammoud, Y., Nelson, W. C., Radune, D., Romero, C. M., Sarria, S., Selengut, J., Shamblin, C., Sullivan, S. A., White, O., Yu, Y., Zafar, N., Zhou, L., and Fraser, C. M. (2004). Structural flexibility in the Burkholderia mallei genome. Proc. Natl. Acad. Sci. U.S.A. 101, 14246-14251.

Nigg, C., Ruch, J., Scott, E., and Noble, K. (1956). Enhancement of virulence of Malleomyces pseudomallei.J. Bacteriol. 71, 530-541.

O'Quinn, A. L., Wiegand, E. M., and Jeddeloh, J. A. (2001). Burkholderia pseudomallei kills the nematode Caenorhabditis elegans using an endotoxin-mediated paralysis. Cell. Microbiol. 3, 381-393.

Owen, S. J., Batzloff, M., Chehrehasa, F., Meedeniya, A., Casart, Y., Logue, C. A., Hirst, R. G., Peak, I. R., MackaySim, A., and Beacham, I. R. (2009). Nasal-associated lymphoid tissue and olfactory epithelium as portals of entry for Burkholderia pseudomallei in murine Melioidosis. J. Infect. Dis. 199, 1761-1770.

Pilatz,S., Breitbach, K.,Hein, N., Fehlhaber, B., Schulze, J., Brenneke, B., Eberl, L., 
and Steinmetz, I. (2006). Identification of Burkholderia pseudomallei genes required for the intracellular life cycle and in vivo virulence. Infect. Immun. 74, 3576-3586.

Propst, K. L., Troyer, R. M., Kellihan, L. M., Schweizer, H. P., and Dow, S. W. (2010). Immunotherapy markedly increases the effectiveness of antimicrobial therapy for treatment of Burkholderia pseudomallei infection. Antimicrob. Agents Chemother. 54, 1785-1792.

Reckseidler, S. L., DeShazer, D., Sokol, P. A., and Woods, D. E. (2001). Detection of bacterial virulence genes by subtractive hybridization: identification of capsular polysaccharide of Burkholderia pseudomallei as a major virulence determinant. Infect. Immun. 69, 34-44.

Reznik, G. K. (1990). Comparative anatomy, physiology, and function of the upper respiratory tract. Environ. Health Perspect. 85, 171-176.

Santanirand, P., Harley, V.S., Dance, D. A., Drasar, B.S., and Bancroft, G. J. (1999). Obligatory role of gamma interferon for host survival in a murine model of infection with Burkholderiapseudomallei. Infect. Immun. 67, 3593-3600.

Sarkar-Tyson, M., Smither, S. J., Harding, S. V., Atkins, T. P., and Titball, R. W. (2009). Protective efficacy of heat-inactivated B. thailandensis, B. mallei or B. pseudomallei against experimental melioidosis and glanders. Vaccine 27, 4447-4451.

Simpson, A. J., Smith, M. D., Weverling, G. J., Suputtamongkol, Y., Angus, B. J., Chaowagul, W., White, N. J., van Deventer, S. J., and Prins, J. M. (2000). Prognostic value of cytokine concentrations (tumor necrosis factor-alpha, interleukin-6, and interleukin-10) and clinical parameters in severe melioidosis. J. Infect. Dis. 181, 621-625.

Smith, M. D., Angus, B. J., Wuthiekanun, V., and White, N. J. (1997). Arabinose assimilation defines a nonvirulent biotype of Burkholderia pseudomallei. Infect. Immun. 65, 4319-4321.

Sprague, L. D., and Neubauer, H. (2004). Melioidosis in animals: a review on epizootiology, diagnosis and clinical presentation. J. Vet. Med. B Infect. Dis. Vet. Public Health 51, 305-320.

Srilunchang, T., Proungvitaya, T., Wongratanacheewin, S., Strugnell, R., and Homchampa, P. (2009). Construction and characterization of an unmarked aroC deletion mutant of Burkholderia pseudomallei strain A2. Southeast Asian J. Trop. Med. Public Health 40, 123-130.
Srisurat, N., Sermswan, R. W., Tatawasart, U., and Wongratanacheewin, S. (2010). Bacterial loads and antibody responses in $\mathrm{BALB} / \mathrm{c}$ mice infected with low and high doses of Burkholderia pseudomallei. Am. J. Trop. Med. Hyg. 82, 1102-1105.

Steward, J., Piercy, T., Lever, M. S., Nelson, M., Simpson, A. J., and Brooks, T. J. (2005). Comparison of gatifloxacin, moxifloxacin and ciprofloxacin for treatment of experimental Burkholderia pseudomallei infection. J. Antimicrob. Chemother. 55, 523-527.

$\mathrm{Su}, \mathrm{X}$., Looney, M., Robriquet, L., Fang, X., and Matthay, M. A. (2004). Direct visual instillation as a method for efficient delivery of fluid into the distal airspaces of anesthetized mice. Exp. Lung Res. 30, 479-493.

Sulaiman, S., Othman, M.Z., and Aziz, A. H. (2000). Isolations of enteric pathogens from synanthropic flies trapped in downtown Kuala Lumpur. J. Vector Ecol. 25, 90-93.

Suputtamongkol, Y., Kwiatkowski, D., Dance, D. A., Chaowagul, W., and White, N. J. (1992). Tumor necrosis factor in septicemic melioidosis. J. Infect. Dis. 165, 561-564.

Tan, G. Y., Liu, Y., Sivalingam, S. P., Sim, S. H., Wang, D., Paucod, J. C., Gauthier, Y., and Ooi, E. E. (2008). Burkholderia pseudomallei aerosol infection results in differential inflammatory responses in BALB/C and C57Bl/ $/ 6$ mice. J. Med. Microbiol. 57, 508-515.

Taweechaisupapong, S., Kaewpa, C., Arunyanart, C., Kanla,P.,Homchampa, P., Sirisinha, S., Proungvitaya, T., and Wongratanacheewin, S. (2005). Virulence of Burkholderia pseudomallei does not correlate with biofilm formation. Microb. Pathog. 39, 77-85.

Thomas, R. J., Webber, D., Collinge, A., Stagg, A. J., Bailey, S. C., Nunez, A., Gates, A., Jayasekera, P. N., Taylor, R. R., Eley, S., and Titball, R. W. (2009). Different pathologies but equal levels of responsiveness to the recombinant $\mathrm{F} 1$ and $\mathrm{V}$ antigen vaccine and ciprofloxacin in a murine model of plague caused by small- and largeparticle aerosols. Infect. Immun. 77, 1315-1323.

Titball, R.W., Russell,P., Cuccui, J., Easton, A., Haque, A., Atkins, T., Sarkar-Tyson, M., Harley, V., Wren, B., and Bancroft, G. J. (2008). Burkholderia pseudomallei: animal models of infection. Trans. R. Soc. Trop. Med. Hyg. 102(Suppl. 1), S111-S116.

Ulett, G. C., Currie, B. J., Clair, T. W., Mayo, M., Ketheesan, N., Labrooy, J., Gal, D., Norton, R., Smith, C. A.,
Barnes, J., Warner, J., and Hirst, R. G. (2001). Burkholderia pseudomallei virulence: definition, stability and association with clonality. Microbes Infect. 3, 621-631.

Ulett, G. C., Ketheesan, N., Clair, T. W. McElnea, C. L., Barnes, J. L., and Hirst, R. G. (2002). Analogous cytokine responses to Burkholderia pseudomallei strains contrasting in virulence correlate with partial cross-protection in immunized mice. Infect. Immun. 70 3953-3958.

Ulett, G. C., Ketheesan, N., and Hirst, R. G. (2000). Proinflammatory cytokine mRNA responses in experimental Burkholderia pseudomallei infection in mice. Acta Trop. 74, 229-234.

Ulrich, R. L., Deshazer, D., Brueggemann, E. E., Hines, H. B., Oyston, P. C., and Jeddeloh, J. A. (2004). Role of quorum sensing in the pathogenicity of Burkholderia pseudomallei. J. Med. Microbiol. 53, 1053-1064.

Valade, E., Thibault, F. M., Gauthier, Y. P., Palencia, M., Popoff, M. Y., and Vidal, D. R. (2004). The PmlI-PmlR quorum-sensing system in Burkholderia pseudomallei plays a key role in virulence and modulates production of the MprA protease. J. Bacteriol. 186 2288-2294.

van Schaik, E., Tom, M., Devinney, R., and Woods, D. E. (2008). Development of novel animal infection models for the study of acute and chronic Burkholderia pseudomallei pulmonary infections. Microbes Infect. 10, 1291-1299.

van Schaik, E. J., Tom, M., and Woods, D.E. (2009). Burkholderia pseudomallei isocitrate lyase is a persistence factor in pulmonary melioidosis: implications for the development of isocitrate lyase inhibitors as novel antimicrobials. Infect. Immun. 77, 4275-4283.

Warawa, J., and Woods, D. E. (2005) Type III secretion system cluster 3 is required for maximal virulence of Burkholderia pseudomallei in a hamster infection model. FEMS Microbiol. Lett. 242, 101-108.

Warawa, J. M., and Gherardini, F. C. (2010). "Modeling of acute respiratory melioidosis and glanders," in National Institute of Allergy and Infectious Diseases, NIH Volume 3, Intramural Research, ed.V.S. Georgiev (New York, NY: Humana Press), 117-121.

Warawa, J. M., Long, D., Rosenke, R., Gardner, D., and Gherardini, F. C. (2009). Role for the Burkholderia pseudomallei capsular polysaccharide encoded by the wcb operon in acute disseminated melioidosis. Infect. Immun. 77, 5252-5261.

West,T.E.,Myers,N.D.,Limmathurotsakul, D., Liggitt, H. D., Chantratita, N., Peacock, S. J., and Skerrett, S. J. (2010). Pathogenicity of high-dose enteral inoculation of Burkholderia pseudomallei to mice. Am. J. Trop. Med. Hyg. 83, 1066-1069.

Wikraiphat, C., Charoensap, J., Utaisincharoen, P., Wongratanacheewin, S., Taweechaisupapong, S., Woods, D. E., Bolscher, J. G., and Sirisinha, S. (2009). Comparative in vivo and in vitro analyses of putative virulence factors of Burkholderia pseudomallei using lipopolysaccharide, capsule and flagellin mutants. FEMS Immunol. Med. Microbiol. 56, 253-259.

Wong, K. T., Puthucheary, S. D., and Vadivelu, J. (1995). The histopathology of human melioidosis. Histopathology 26, 51-55.

Wong, K. T., Vadivelu, J., Puthucheary, S. D., and Tan, K. L. (1996). An immunohistochemical method for the diagnosis of melioidosis. Pathology $28,188-191$.

Woods, D. E., Jones, A. L., and Hill, P. J. (1993). Interaction of insulin with Pseudomonas pseudomallei. Infect. Immun. 61, 4045-4050.

Yap, E. H., Thong, T. W., Tan, A. L., Yeo, M., Tan, H. C., Loh, H., Teo, T. P., Thong, K. T., Singh, M., and Chan, Y. C. (1995). Comparison of Pseudomonas pseudomallei from humans, animals, soil and water by restriction endonuclease analysis. Singapore Med. J. 36, 60-62.

Conflict of Interest Statement: The author declares that the research was conducted in the absence of any commercial or financial relationships that could be construed as a potential conflict of interest.

Received: 08 November 2010; accepted: 13 December 2010; published online: 29 December 2010.

Citation: Warawa JM (2010) Evaluation of surrogate animal models of melioidosis. Front. Microbio. 1:141. doi: 10.3389/ fmicb.2010.00141

This article was submitted to Frontiers in Cellular and Infection Microbiology, a specialty of Frontiers in Microbiology.

Copyright ( $\odot 2010$ Warawa. This is an open-access article subject to an exclusive license agreement between the authors and the Frontiers Research Foundation, which permits unrestricted use, distribution, and reproduction in any medium, provided the original authors and source are credited. 